\title{
Human body finite element model as an instrument for the improvement of passive safety
}

\author{
L. Č́ihalová* \& L. Hynčík \\ New Technologies Research Center, University of West Bohemia, Plzeñ, Czech Republic \\ *Corresponding author: cihalin@ntc.zcu.cz
}

\begin{abstract}
Recently the virtual finite element human body models have become important when used to improve the passive safety of vehicle occupants. The human body models have a significant advantage over dummies, since they are able not only to predict injuries, but also to model the whole injury mechanism. This enables the detailed analysis of injuries, and hence a more precise optimization of safety systems. To be able to use the models for this purpose, an objective model of the human body needs to be created. Such a human body model, ROBBY, is being developed at the University of West Bohemia (UWB) in cooperation with the ESI Group. This model is still being updated to be a more realistic model. The aim of this study was to improve the thoracic part of the human body model by the implementation of a created thoracic model to the existing ROBBY model and use the updated model as a tool for safety evaluation. Two types of sled tests were performed to compare the behavior of the updated model ROBBY and cadavers. The first sled test was performed at $30 \mathrm{~km} / \mathrm{h}$ without airbag, and the second at $50 \mathrm{~km} / \mathrm{h}$ with airbag. A comparison of the response of the thorax-abdomen complex for the model and cadavers was performed.
\end{abstract}

KEY WORDS: Sled test, ROBBY model, cadaver, biomechanics, frontal impact

\section{INTRODUCTION}

In the European Union, the assessment of the protection offered by a vehicle to a restrained occupant in the case of a collision is based on biomechanical data measured on the HYBRID III crash test dummy, as described by the European Frontal Directive (Directive 96/79/EC). Our presented study is based on the paper of (Vezin et al., 2002), who obtained new biomechanical data of the behavior of the human thorax/shoulder complex under different frontal impact conditions.

Since the response of the human body during various accidents is still the objective of much research, our endeavor is to have a more realistic model of the human model ROBBY developed in UWB in cooperation with the ESI Group, see (Hynčík, 2002). The aim of the presented study was to improve the previously developed model ROBBY in the sense of the integration of a created thoracic model into the model as a whole. To check the reality of the response of the thoracic part of the updated ROBBY model, two types of sled tests were performed. The response of the ROBBY model was compared with the response of cadavers according to (Vezin et al., 2002). The main goal of the study was to show the possibility and advantages of using human body models in virtual safety systems design. 


\section{PREPARATION OF THE MODEL}

(Č́íhalová, 2006) previously created and validated the FE model of the thorax (see Figure 1), whose geometry was based on the Visible Human Project photographs, see (VHP, 2003). This model was consequently scaled, and further it was embedded into the complete human body model ROBBY, see Figure 2. The ROBBY model represents an average adult male. This model belongs to the ROBBY family, which consists of ROBBY2 - a model of a man (on various levels), ROBINA - a model of woman, and BOBBY6 - a model of a child. The family is multi-body-based. The ROBBY model enables the detailed description of impact consequences, since there are modular implementations of a deformable abdomen and thorax. Modular means that a rigid part can be substituted with a deformable one.
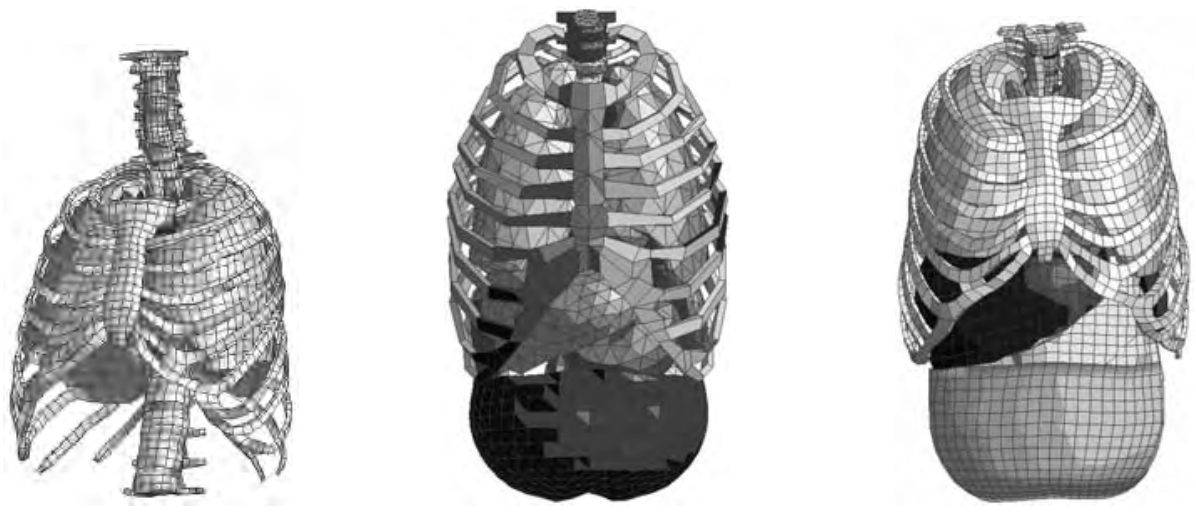

Figure 1: The developed thoracic model, old and updated thorax-abdomen complex of ROBBY model

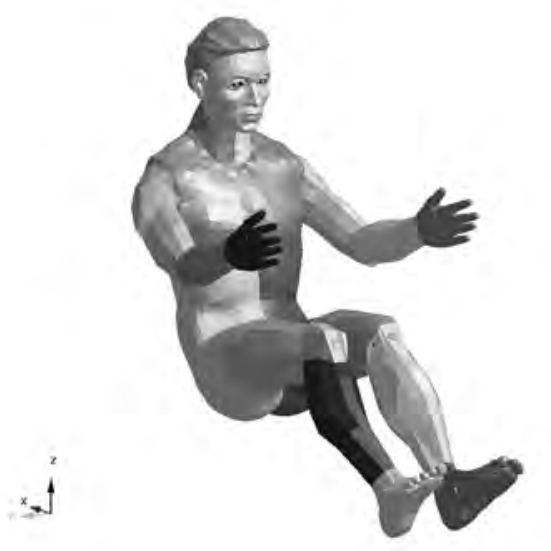

Figure 2: ROBBY model

\section{FRONTAL SLED TEST}

The laboratory sled tests have been designed to simulate the inertial effects of real vehicle frontal crashes. Generally, the sled test studies are useful for understanding the occupant kinematics and the injury mechanisms according to the restraint systems. In the past, many frontal sled tests have been performed with different subjects seated in the driver position and different restraint conditions by (Kallieris et al., 1995), (Kleinberger et al., 1998), etc. In this study, the sled tests were simulated according to (Vezin et al., 2002). He performed 
sled tests in LBMC (Laboratoire de Biomécanique et de Mécanique des Choes); and tests are similar to those used at the University of Heidelberg by (Kallieris, 2001). In Vezin's study, two series of tests with Post Mortem Human Subject (PMHS), Hybrid III and Thor$\alpha$ dummies were conducted.

The first series of tests according to (Vezin et al., 2002) were performed at a lower velocity, $30 \mathrm{~km} / \mathrm{h}$, with a $15 \mathrm{~g}$ peak sled deceleration pulse (see Figure 3), using a lap belt and a shoulder belt. The second test was performed at a higher velocity, $50 \mathrm{~km} / \mathrm{h}$, with a higher deceleration pulse of about $22 \mathrm{~g}$ (see Figure 3), and a restraint system composed of a lap belt, a shoulder belt and an airbag. These deceleration laws were chosen in order to evaluate the responses of the dummies under such impact conditions that can lead to no, or low, injuries risk.

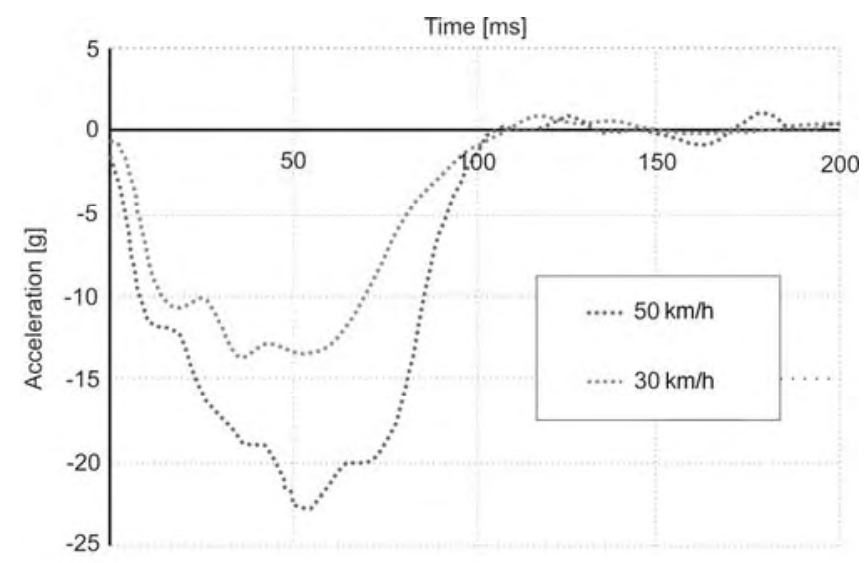

Figure 3: The sled deceleration time history according to (Vezin et al., 2002)

To simulate these tests, the seat geometry was chosen to correspond to a standard mid-sized car. The seat pan had a slope of $18^{\circ}$ and the footrest a slope of $43^{\circ}$. The feet of the surrogate were strapped to the footrest. The seat was rigid. The model was restrained using a three point belt system and, in case of the $50 \mathrm{~km} / \mathrm{h}$ test, by the airbag. The belt restraint system includes a retractor, force limiter and a slip-ring between the shoulder belt and the lap belt. The setup of sled tests is visualized below, see Figure 4.
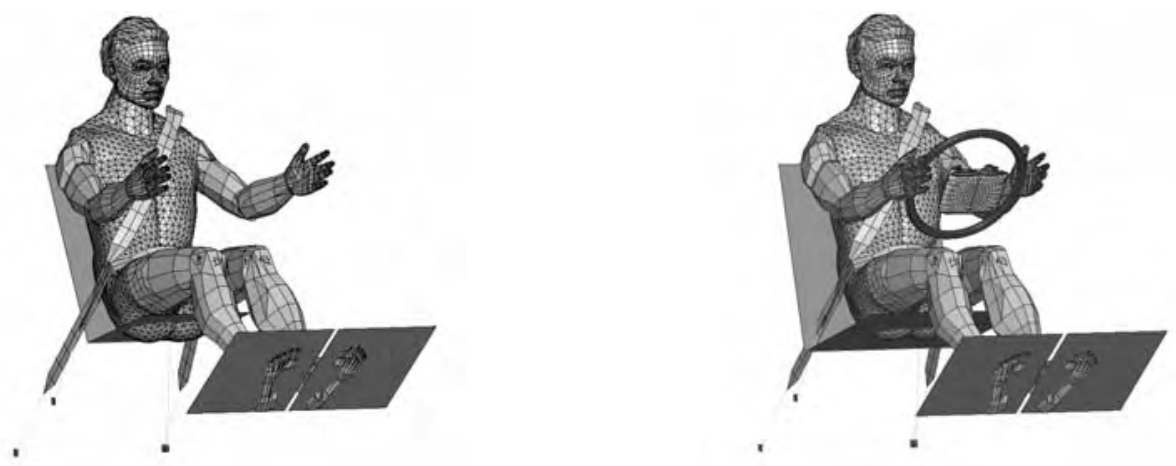

Figure 4: The setup of sled tests: at lower velocity without airbag (30 km/h test) and at higher velocity with airbag $(50 \mathrm{~km} / \mathrm{h}$ test)

The time dependencies of T1, T8, T12, lower and upper sternum accelerations; and the shoulder and lap belt load time history were investigated to compare the behavior of the updated ROBBY model with the behavior of cadavers investigated by (Vezin et al., 2002). All investigated dependencies were filtered by CFC60, see (PAMCRASH/SAFE ${ }^{\mathrm{TM}}$, 2007). 


\subsection{BELT LOADS}

Figure 5 represents shoulder belt load time histories for the $30 \mathrm{~km} / \mathrm{h}$ and $50 \mathrm{~km} / \mathrm{h}$ tests. The load in the shoulder belt rises rapidly from 30 to $75 \mathrm{~ms}$. The force-limiting system enters the play after $75 \mathrm{~ms}$ for the $50 \mathrm{~km} / \mathrm{h}$ test and the load is sustained for approximately $10 \mathrm{~ms}$. After this time the load declines. For the $30 \mathrm{~km} / \mathrm{h}$ test without airbag, the load limit of $4 \mathrm{kN}$ is not reached. As can be seen from Figure 5 the simulation results are in agreement with experimental results. The lap belt loads for both tests are presented in Figure 6 .
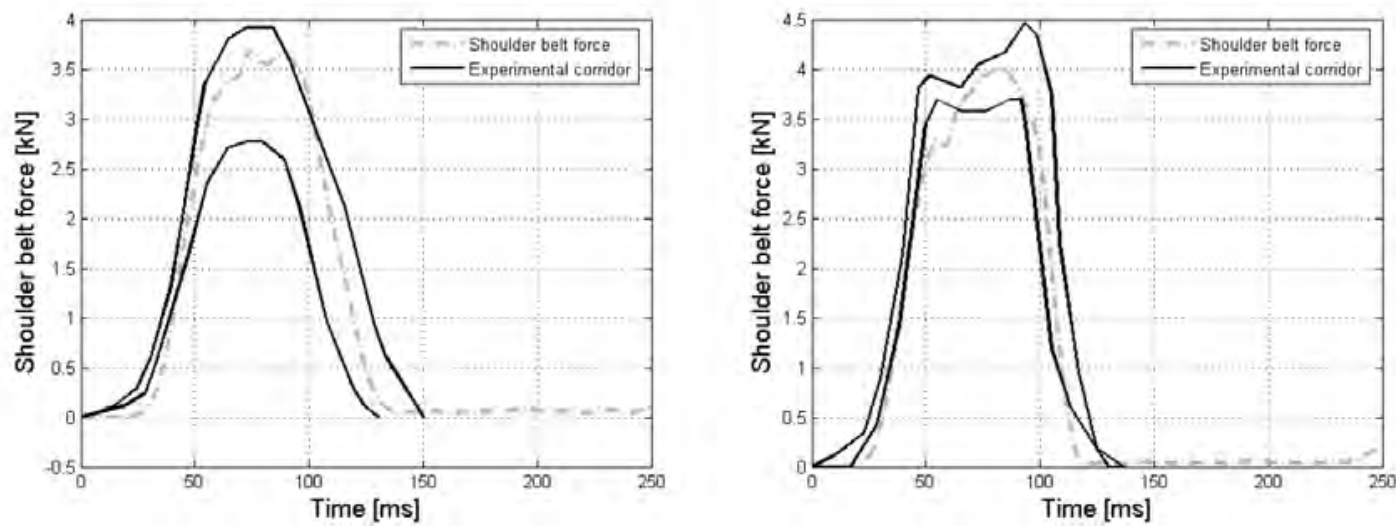

Figure 5: The shoulder belt load time history for the $30 \mathrm{~km} / \mathrm{h}$ test and the $50 \mathrm{~km} / \mathrm{h}$ test
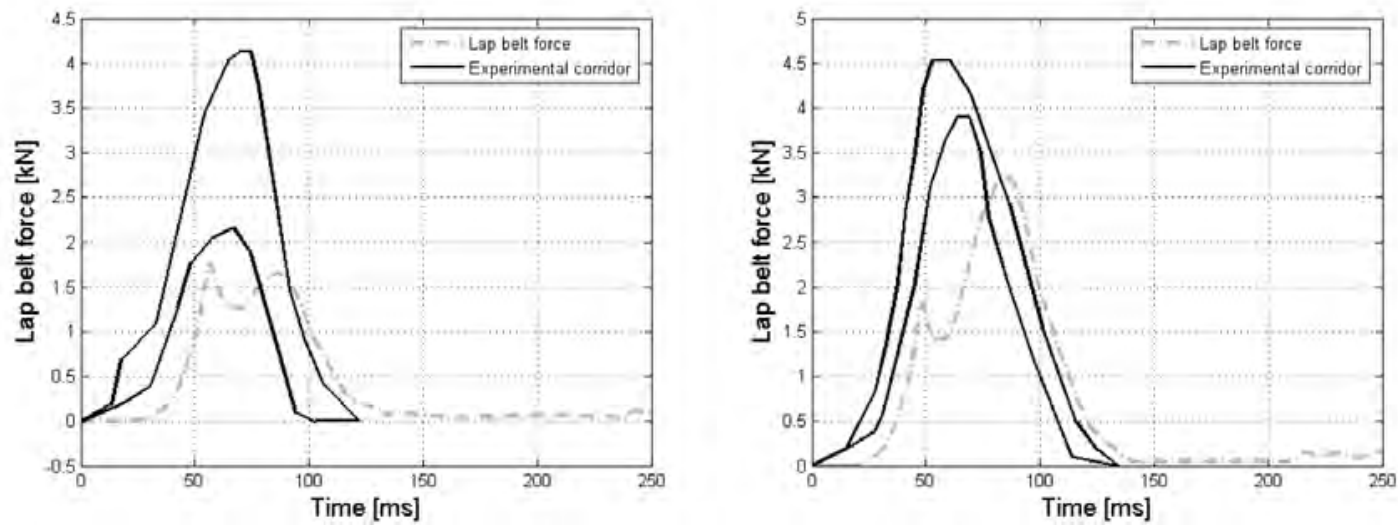

Figure 6: The lap belt load time history for the $30 \mathrm{~km} / \mathrm{h}$ test and the $50 \mathrm{~km} / \mathrm{h}$ test

The results of lap belt loading are in agreement with reality in the phase of unloading. During the phase of loading the simulation lap belt load is smaller than experimental one. This could have been caused by the response of the abdomen; it seems that it is softer than the real abdomen. Hence, there arises the necessity to improve this part of ROBBY model in the future.

\subsection{THORACIC SPINE ACCELERATION}

The behavior of the thoracic spine can be investigated through the dynamics of the T8 and T12 vertebrae. Results of the simulation for both tests show two peaks, see Figure 7 and 8 . However, in the case of the $30 \mathrm{~km} / \mathrm{h}$ test without airbag the second peak is lower than the first one. In the case of the $50 \mathrm{~km} / \mathrm{h}$ test with airbag the second peak is comparable with the first one. The first peak of the $50 \mathrm{~km} / \mathrm{h}$ test at $50 \mathrm{~ms}$ corresponds to the load 
of the thorax by the shoulder belt and the second peak at $80-90 \mathrm{~ms}$ arises as a consequence of the load of the chest by the airbag.
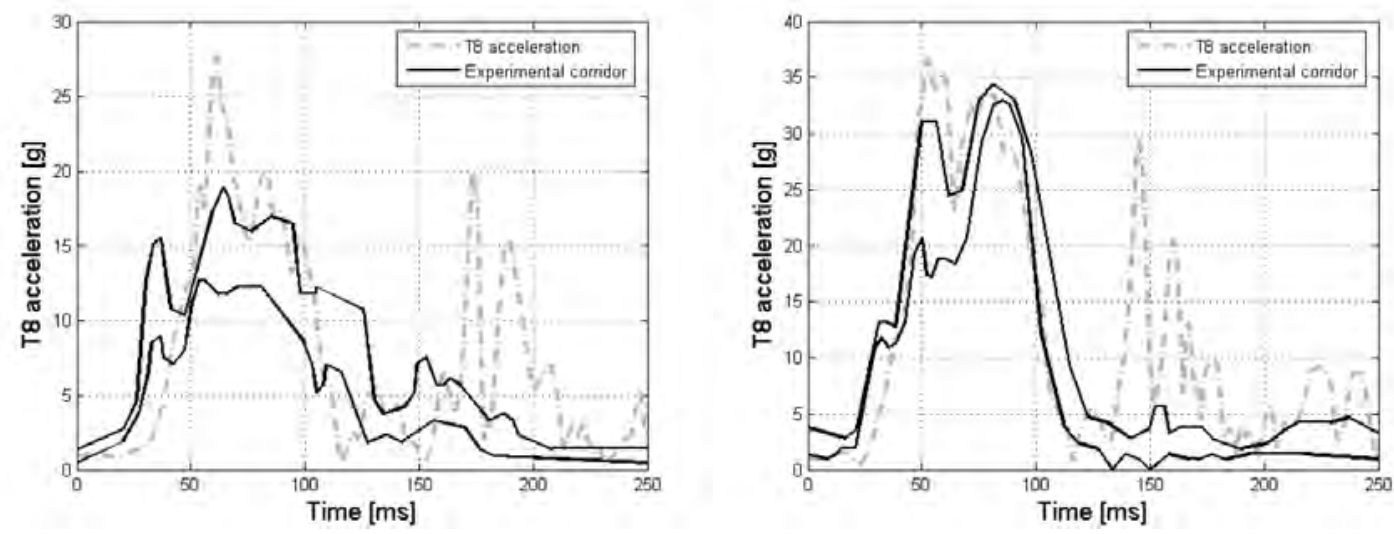

Figure 7: The T8 resultant acceleration time history for $30 \mathrm{~km} / \mathrm{h}$ and $50 \mathrm{~km} / \mathrm{h}$ tests
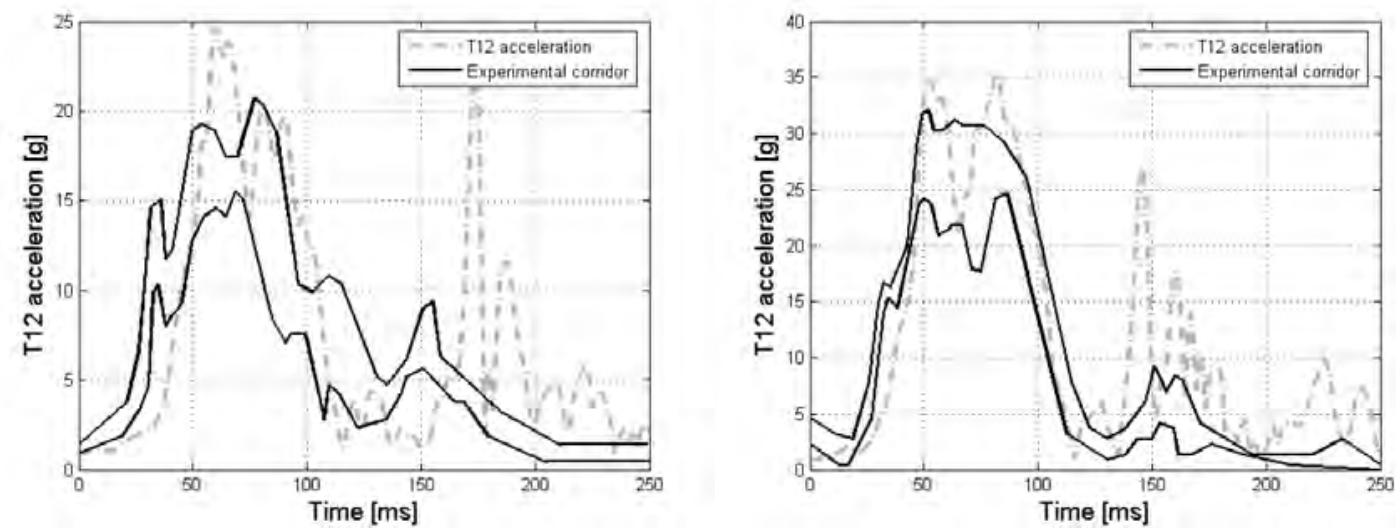

Figure 8: The $T 12$ resultant acceleration time history $30 \mathrm{~km} / \mathrm{h}$ and $50 \mathrm{~km} / \mathrm{h}$ tests

At the beginning, the accelerations for both tests rise rather slightly compared with the accelerations of cadaver. During the $30 \mathrm{~km} / \mathrm{h}$ tests the peaks of accelerations around $60 \mathrm{~ms}$ are a little higher than those of the cadavers. However, in the increase and decline phase the results are comparable.

\subsection{UPPER SPINE ACCELERATION}

The upper spine behavior can be studied through the dynamics of the T1 vertebra. T1 accelerations for both tests are visualized in Figure 9.
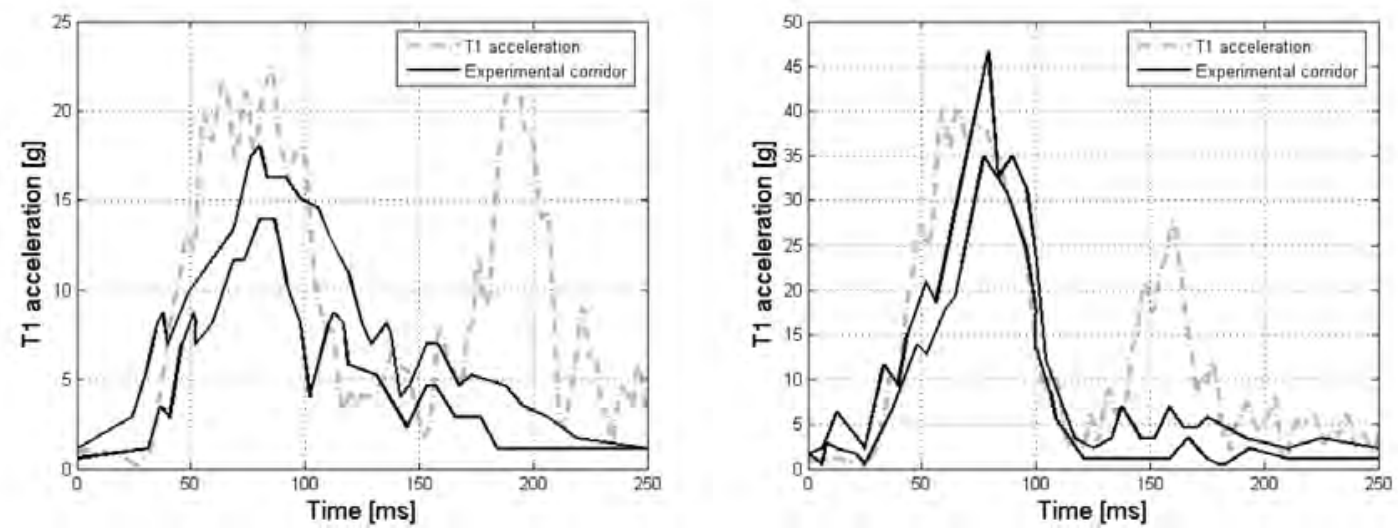

Figure 9: The T1 resultant acceleration time history for $30 \mathrm{~km} / \mathrm{h}$ and $50 \mathrm{~km} / \mathrm{h}$ tests 
The accelerations in the $30 \mathrm{~km} / \mathrm{h}$ test rise above the acceleration of the experiment. However, in the case of the $50 \mathrm{~km} / \mathrm{h}$ test, the acceleration of the model corresponds to the response of the cadaver.

\subsection{STERNUM ACCELERATION}

Although the T1 corresponds to the upper sternum and T8 corresponds to the lower sternum in a geometrical way, their accelerations are rather different, see Figure 7, 9, 10 and 11.
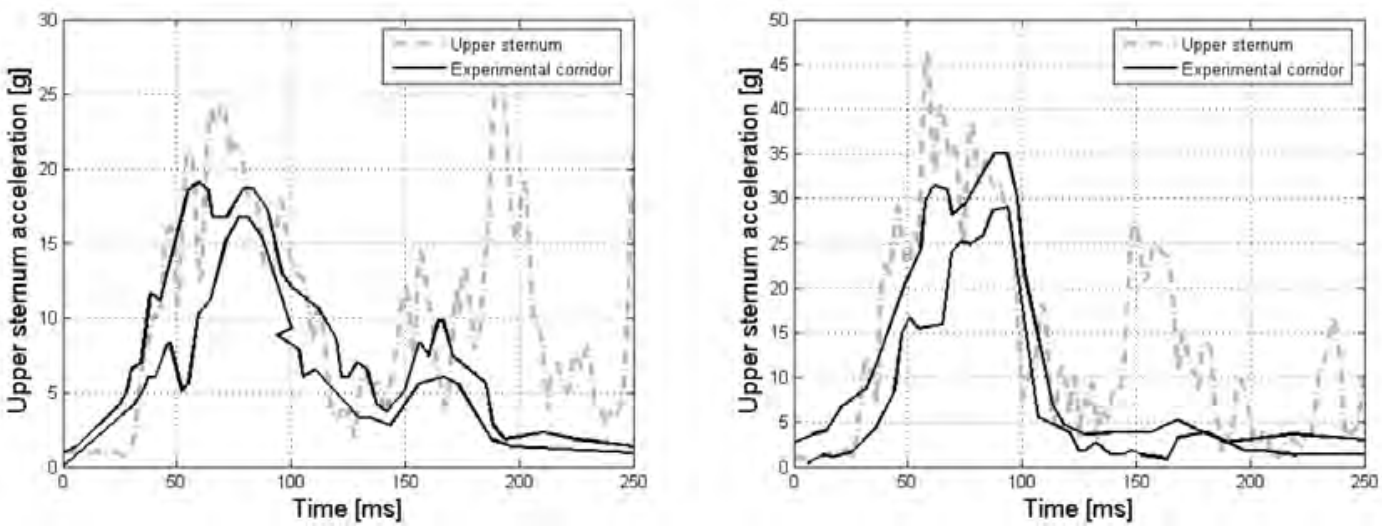

Figure 10: The upper sternum resultant acceleration time history for the $30 \mathrm{~km} / \mathrm{h}$ and $50 \mathrm{~km} / \mathrm{h}$ tests
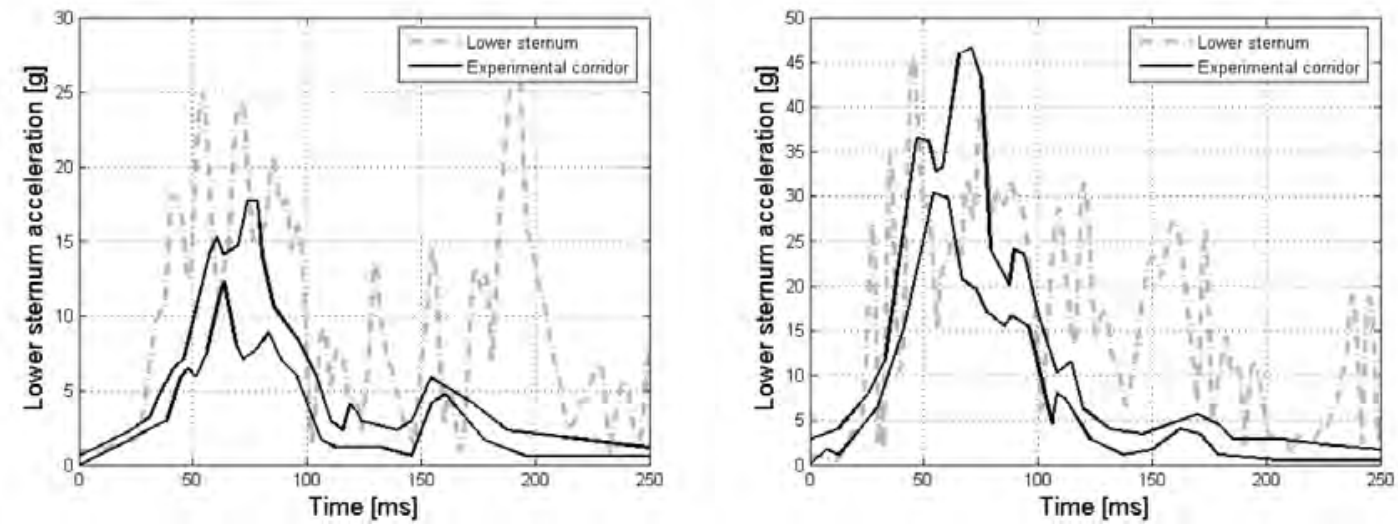

Figure 11: The lower sternum resultant acceleration time history for the $30 \mathrm{~km} / \mathrm{h}$ and $50 \mathrm{~km} / \mathrm{h}$ tests

The increase and decline phases of upper sternum accelerations in both tests are in agreement with experimental results. Only the first peak of acceleration is a little higher than the experimental one, see Figure 10. In the case of lower sternum acceleration more dissimilarities can be observed, see Figure 11. This could be caused by the problem with abdomen and the fact that the response of the lower sternum is influenced by the abdomen. However, in both test results it can be seen that the trend function of both results is similar to the experimental one.

In summary, all results agree with the experimental ones. Hence the simulation results belong to the corridors or are close to them. The first peaks of all simulation results are rather higher than the experimental ones. This is influenced by the properties of restraining systems. 
Consequently, other peaks are evident around $150 \mathrm{~ms}$ in all results. These correspond to the interaction of the body with the seat.

\subsection{RIBCAGE ACCELERATION}

Figure 12 represents the accelerations of the 4th and 6 th rib (left and right) at $30 \mathrm{~km} / \mathrm{h}$ without airbag, and at $50 \mathrm{~km} / \mathrm{h}$ with airbag. The direction of the measured acceleration (one component) was perpendicular to the rib, hence measured in the $\mathrm{X}$ axis according to (Vezin et al., 2002).
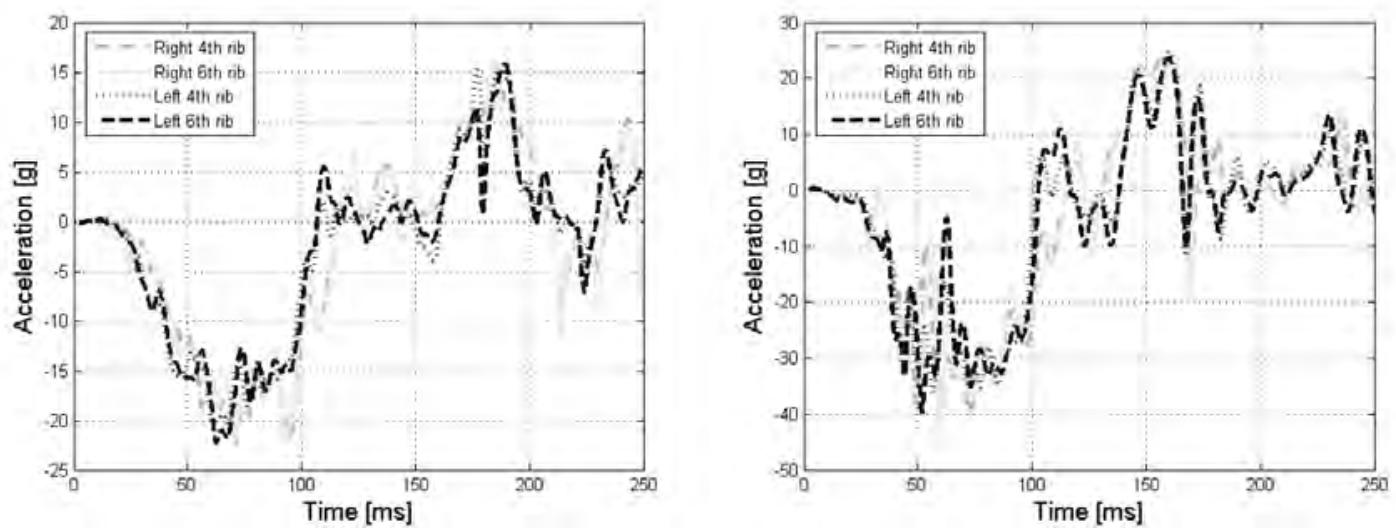

Figure 12: Rib acceleration $X$ time history for the $30 \mathrm{~km} / \mathrm{h}$ and $50 \mathrm{~km} / \mathrm{h}$ tests

There was no significant difference between the accelerations of 4 th and 6th rib on the left and right side. At $30 \mathrm{~km} / \mathrm{h}$ the deceleration was faster on the left ribs than on the right ribs, which indicates a greater chest deflection on this side. At the $50 \mathrm{~km} / \mathrm{h}$ the thorax is deformed on the left side only a little more than on the right side and therefore the difference between individual accelerations is not so appreciable.

\section{INJURY INVESTIGATION}

The great advantage of the ROBBY model is its ability to predict injuries sustained during traffic accidents. The often used injury criteria (Schmidt et al., 2004) such as HIC (Head Injury Criterion) (see Table 1) for head, compression $\mathrm{C}$, rate of deformation $\mathrm{V}$, rate of compression $\mathrm{VC}$ for thorax and abdomen, acceleration of spine and loading of sternum can be investigated on this model. Moreover, since the thoracic part of the ROBBY model was modeled as deformable, it allows a view of the deformation of internal organs, such as lungs, heart and aorta and bony parts, such as sternum, ribs and vertebrae.

Table 1: The evaluation of HIC for ROBBY and comparison with results according to (Vezin et al, 2002).

\begin{tabular}{|c|c|c|}
\hline & $30 \mathrm{~km} / \mathrm{h}$ test & $50 \mathrm{~km} / \mathrm{h}$ test \\
\hline Cadaver & 160 & 620 \\
\hline Hybrid III & 86 & 230 \\
\hline Thor- $\alpha$ & 107 & 427 \\
\hline ROBBY & 132 & 774 \\
\hline
\end{tabular}




\section{CONCLUSION}

The aim of this study was to integrate the created and validated model of the human thorax into the previously developed model ROBBY presenting a model of the average adult male. The reality of the updated model was validated by virtue of two types of sled tests according to (Vezin et al., 2002). The response of the thorax model was compared with the response of the cadaver thorax. The results of the comparison show that the updated model ROBBY is a satisfactory approximation of the human body. There are some deviations visualized by the peaks after $150 \mathrm{~ms}$ in all the results. However, these deviations occur after the unloading phase and they could have been caused by the bad interaction of the model with the back seat. This suggests the objective for the following improvement of the ROBBY model, i.e., to improve the deformable model of the abdomen and to validate it in the future, using the sled test. In conclusion, the updated model is a very good approximation of the human body and moreover it has the ability to predict injuries. Therefore, its continued usage in virtual safety systems design could be possible.

\section{ACKNOWLEDGEMENT}

This study was supported by the project FT-TA/024 of the Ministry of Industry and Trade of the Czech Republic. Great thanks belong to ESI Group International and the John H. and Anny Bowles Foundation.

\section{REFERENCES}

Č́íhalová, L, 2006. Development of biomechanical deformable thoracic model, Journal Engineering mechanics, vol. 13, No. 6, pp. 453-465.

Directive 96/79/EC of the European Parliament and of the Council of 16 December 1996, on the protection of occupants of motor vehicles in the event of a frontal impact. Directive 199/98/EC, Amendment 15 December 1999, Official Journal of the European Communities, Brussels.

Hynčík, L., 2002: Biomechanical model of abdominal organs and tissue for car crash test purposes, Ph.D.Thesis, University of West Bohemia, Plzeň.

Kallieris, D., 2001: Personal communication, University of Heidelberg, Germany.

Kallieris, D., Rizzeti, A., Mattern, R., Morgan, R., Eppinger, R., and Keenan, L., 1995. On the synergism of the driver air bag and the 3-point belt in frontal crashes, Proceeding 39th Stapp Car Crash Conference, pp. 389-401.

Kleinberger, M., Sun, E., Eppinger, R., Kuppa, S., Saul, R., 1998. Development of Improved Injury Criteria for the Assessment of Advanced Automotive Restraint System, NHTSA report.

PAM-CRASH/SAFE ${ }^{\mathrm{TM}}$, Notes Manual, Version 2007.

Vezin, P., Bruyere-Garnier, K., Bermond, F., Verriest, J. V., 2002. Comparison of HYBRID III, Thor- $\alpha$ and PMHS Response in Frontal Sled Tests, Stapp Car Crash Journal, vol. 46, pp. 1-26.

Schmitt, K.U., Niederer, P., Walz, F., 2004. Trauma Biomechanics, Introduction to Accidental Injury, Springer, Zurich.

Visible Human Project (VHP), U. S. National library of medicine, 2003. 